\title{
0100. Apelin is cardioprotective and life-saving over dobutamine in a murine model of endotoxin-induced myocardial dysfunction
}

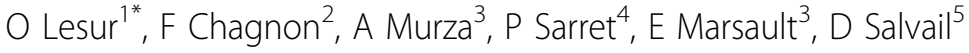 \\ From ESICM LIVES 2014 \\ Barcelona, Spain. 27 September - 1 October 2014
}

\section{Introduction}

Dobutamine (DOB) is the actual recommended b-adrenergic inotropic drug to support sepsis-induced myocardial dysfunction when cardiac output index is still low after preload correction. In this context, DOB cardiovascular response predicts outcome in septic shock. Alternative supportive and safer therapies are however mandatory because:

1) only $35-45 \%$ of septic patients do respond to DOB, and

2) numerous side-effects of DOB can be observed, including potential harmful impact on cardiomyocyte function. Apelin (APLN) is a powerful inotrope, is widely expressed by the cardiovascular system with its receptor APJ-R, and should be considered as an alternative noncatecholaminergic support.

\section{Objectives}

Perform a comparative evaluation of APLN-13 (APLN active peptide) vs DOB in terms of hemodynamic efficacy, cardioprotection and outcome in a model of "sepsisinduced cardiac dysfunction".

\section{Methods}

A rat model of LPS-induced myocardial dysfunction (E. Coli 055:B5, 10-12mg/kg intraperitoneal).

\section{Interventions}

APLN-13 vs DOB $(0.23$ vs $7.5 \mu \mathrm{g} / \mathrm{kg} / \mathrm{min}$ i.v continuous infusion respectively, as determined by preliminary experiments with or without "in parallel" fluid resuscitation (saline, $2 \mathrm{~mL} / \mathrm{kg} / \mathrm{hr}$ ).

\section{Time-course}

0-6-18h.

\section{Outcomes}

In vivo: echocardiography, final hemodynamics; urine output, weight and plasma volume variation, survival study, ex vivo: Langendorff $\mathrm{dP} / \mathrm{dt}$, in vitro: $\mathrm{APJ}-\mathrm{R}$ and beta1-adrenergic receptor (AR) myocardial expressions, Pi3K/Akt/GSK3/mTOR activation-expression profiles, cTnI (troponin, myocardial injury) and cleaved caspase3 (apoptosis).

\section{Results}

Both drugs restored LPS-induced fall of left ventricular ejection fraction (LVEF) with dominant chronotropic impact and mean arterial pressure (MAP) restoration for $\mathrm{DOB}$, and lower peripheral vascular resistances (PVR) for APLN. APJ-R but not beta1 AR myocardial expressions were upregulated by LPS challenge $(\mathrm{p}<$ 0.05). The deepness the induced LVEF drop, the higher the $\mathrm{dP} / \mathrm{dt}$ response to APLN but not to DOB $(\mathrm{p}<0.05)$. In 18h LPS-challenged hearts, Langendorff assays peak $\mathrm{dP} / \mathrm{dt}$ responses were $3 \mathrm{nM}$ and $100 \mathrm{nM}$ for APLN and $\mathrm{DOB}$, respectively $(\mathrm{p}<0.05)$. Combining fluid resuscitation with APLN infusion declined urine output (UO) with plasma volume (PV) expansion, whereas DOB induced less PV expansion but more UO $(\mathrm{p}<0.05)$. Survival proportions were clearly distinctive $(\mathrm{p}<0.05)$.

APLN further dampened down LPS-induced overphosphorylation/inhibition of Pi3K/Akt/mTOR/GSK3 and reduced injury/apoptosis (i.e. cTNI and cleaved caspase3 expressions). 


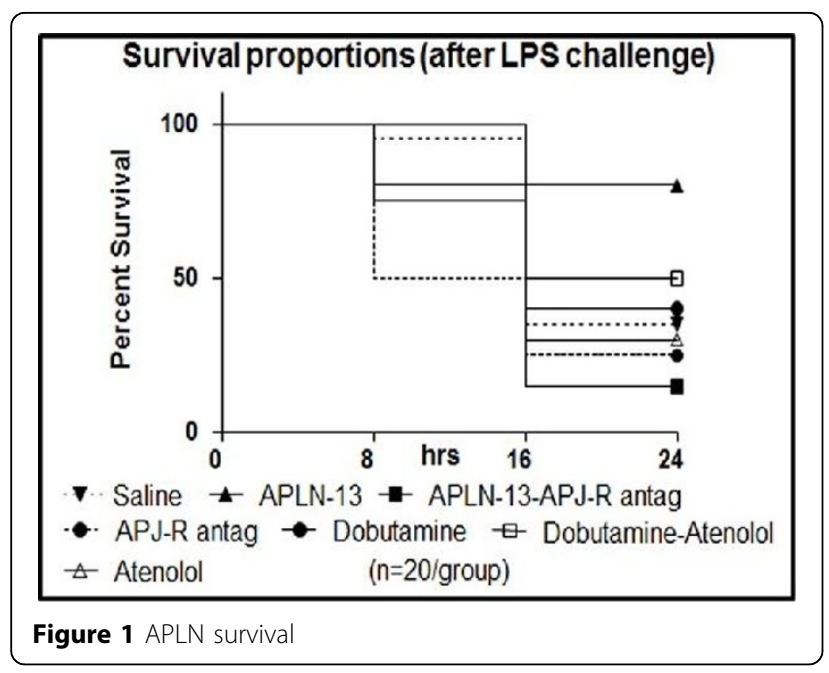

\section{Conclusions}

APLN potentially offers distinctive mechanisms of hemodynamics, cardioprotective effects, and survival benefits, over DOB. Chemical optimization of APLN-13 with more extensive preclinical data, would pave the way for first phase clinical trials.

\section{Grant acknowledgment}

Canadian Heart \& Stroke Foundation.

\section{Authors' details}

'University de Sherbrooke, ICU / Medicine / CHUS, Sherbrooke, Canada. ${ }^{2}$ ICU/Medicine/CRCHUS, Sherbrooke, Canada. ${ }^{3}$ IPS/ U de Sherbrooke, Pharmacology, Sherbrooke, Canada. ${ }^{4}$ IPS/ U de Sherbrooke, Physiologie, Sherbrooke, Canada. ${ }^{5}$ IPS Therapeutique Inc, Sherbrooke, Canada.

Published: 26 September 2014

\section{doi:10.1186/2197-425X-2-S1-P11}

Cite this article as: Lesur et al:: 0100. Apelin is cardioprotective and lifesaving over dobutamine in a murine model of endotoxin-induced myocardial dysfunction. Intensive Care Medicine Experimental 2014 2(Suppl 1):P11.

\section{Submit your manuscript to a SpringerOpen ${ }^{\circ}$ journal and benefit from:}

- Convenient online submission

- Rigorous peer review

- Immediate publication on acceptance

- Open access: articles freely available online

- High visibility within the field

- Retaining the copyright to your article

Submit your next manuscript at $>$ springeropen.com 